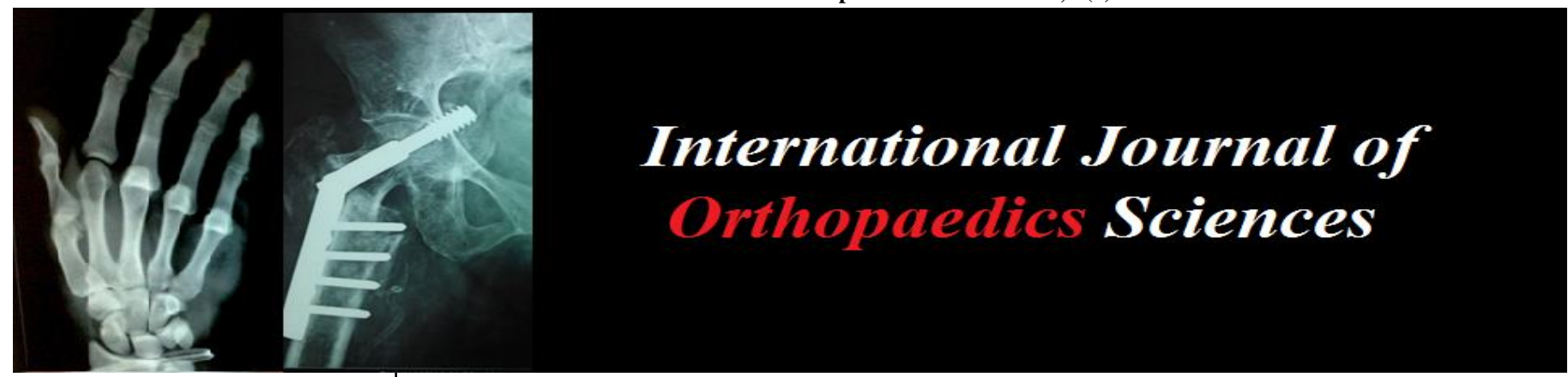

ISSN: $2395-1958$

IJOS 2018; 4(2): 478-481

(C) 2018 IJOS

www.orthopaper.com

Received: 12-02-2018

Accepted: 13-03-2018

Imran I Shaikh

Department of Spine Surgery, Shanghai East Hospital, Tongji University School of Medicine, 150 Jimo Road, Shanghai 200120, China

Surendra K Chaudhary Department of Spine Surgery, Shanghai East Hospital, Tongji University School of Medicine, 150 Jimo Road, Shanghai 200120, China

\section{Li Xinhua}

Department of Spine Surgery, Shanghai East Hospital, Tongji University School of Medicine, 150 Jimo Road, Shanghai 200120, China

\section{Wu Desheng}

Department of Spine Surgery, Shanghai East Hospital, Tongji University School of Medicine, 150 Jimo Road, Shanghai 200120, China
Correspondence

Wu Desheng

Department of Spine Surgery, Shanghai East Hospital, Tongji University School of Medicine, 150 Jimo Road, Shanghai 200120, China

\section{Literature review of quality of life and influencing factors in patients of cervical spondylosis treated by ACDF}

\author{
Imran I Shaikh, Surendra K Chaudhary, Li Xinhua and Wu Desheng
}

DOI: https://doi.org/10.22271/ortho.2018.v4.i2h.72

\section{Abstract}

Introduction: Influence of psychosocial factors on patients of cervical spondylosis need to be calculated as they plays an important role in patient's quality of life (QOL). As anterior cervical discectomy and fusion (ACDF) has become most common surgical approach, since 1958 introduced by Robinson and Smith in patients affected by cervical disc disease like cervical spondylosis. So we have reviewed the literature of psychosocial factors correlated with the physical conditions in patients treated with ACDF. Method and material: We have searched the literature on Pubmed, MEDLINE, EMBASE, PsycINFO, Psyc ARTICLES, Cochrane Library, Web of Science, Elisver, Google scholar, and Baidu scholar limiting results to those published in the English language without limiting year. The key search terms utilized were ACDF, quality of life, cervical spondylosis, anxiety and depression with ACDF, cervical radiculopathy, cervical myelopathies, neck pain, SF-36, HRQOL.

Conclusion: On the base of previous published article men have affected more than women with age $>50$ years. ACDF was the most common procedure used to treat the cervical spondylosis. When it comes to psychosocial factors anxiety and depression was found to be most common influencing factor and neck pain was the physical condition accompanied to those factors. After surgery it was found a significant increase in QOL as ACDF reduces the neck pain which reflect in psychosocial factors as well by significant decrease in anxiety, depression and working ability.

Keywords: ACDF, quality of life, cervical spondylosis, anxiety and depression with ACDF, cervical radiculopathy, cervical myelopathies, neck pain, SF-36, HRQOL

\section{Introduction}

Cervical spondylosis is a degenerative disorder in which formation disc degenerate around amphiarthrodial Joint by adjoining vertebral bodies and disc between them. It is one of most common spinal degenerative disease, which not only affect elders but also young adult once in life. The incidence of cervical spondylosis is 9 out of 10 peoples over 65 years of age. It's noninflammatory process of cervical spine causes paraparesis and quadriparesis ${ }^{[1]}$. The degeneration can eventually worsen and causes either compression of existing cervical spinal nerves or of the cervical spinal cord. Cervical spondylosis clinically described by local pain in neck-shoulder area with or without radiation to arms, numbness, tingling and paresthesia. In later stages spondylotic myelopathy of the upper limb, radiological reduction in intervertebral disc space and formation of marginal osteophytes are found. Posteriorly these osteophytes protrude into the spinal canal and laterally into the intervertebral foramina. These osteophytes cause spinal cord and nerve root impingement, bulging intervertebral disc which would present as local neck stiffness and radicular pain along the offending nerve root. Long-standing compression of the spinal cord can result in irreversible damage including demyelination and necrosis of grey matter ${ }^{[2]}$. Radhakrishnan reported an annual incidence rate of cervical spondylosis related radiculopathy is 83 per 10,000 population in Rochester, Minnesota. Men have affected more than women with peak age $50-54$ years ${ }^{[3]}$

When conservative management failed patients have to undergo, a variety of procedures to treat cervical radiculopathy depends on patient condition and severity. ACDF (anterior cervical discectomy and fusion) has become most common approach, since 1958 introduced by Robinson and Smith in patients affected by cervical disc disease like cervical spondylosis. 
It is a primary procedure performed as anterior cervical discectomy of the herniated disc with endplate and fusion of vertebral bodies for standard stabilization ${ }^{[4]}$. In the past several decades, epidemiological data has suggested a rapidly increasing number of ACDF procedures performed on increasingly elderly patients ${ }^{[30,31,32]}$. Decker and Korinth have explained that ACDF leads to significant improvements in quality-of-life (QOL). ${ }^{[5]}$ More recently, there have been increasing data supporting the role of preoperative psychosocial states affecting operative clinical outcomes, given that conditions such as depression are often prevalent in patients with chronic pain $[25,26]$. The association between depression and neck pain is less clear and not well documented. Relatively few studies have explored the association between preoperative psychological states such as depression with clinical outcomes following anterior or posterior cervical surgery $[27,28]$. One recent study retrospectively analyzed 106 patients who underwent ACDF but did not find a statistically significant association between preoperative depression and postoperative health outcome ${ }^{[29]}$. Purpose of this literature review was to find the health-related quality of life postoperative anterior cervical fusion surgery and its correlation with social or psychological factors.

\section{Method}

At present Report of QOL outcomes have been evaluated by scales via Odom's criteria, SF-36, Beck Depression Inventory scale, neck disability index(NDI), PDQ, PDQ-9, EQ-5D, JOA score and visual analog scale (VAS).[6] Previous studies have verified several demographic and clinical variables that reported a group of patients has same prior ACDF QOL Health states ${ }^{[7,8]}$. The SF-36 scale is divided into 8 dimensions, mainly from a physiological function, physical pain, general health status, muscle power (muscle tone), social function, emotional function and mental health to summarize the life-related quality of the respondents.

An electronic search was done on:Pubmed, MEDLINE, EMBASE, PsycINFO, PsycARTICLES, Cochrane Library and Web of Science, Elisver to identify the relevant paper.

2.1 Key words search: ACDF, quality of life, cervical spondylosis, anxiety and depression with ACDF, cervical reticulopathy, cervical mylopathies, neck pain, SF-36, HRQOL.

2.2 Inclusion criteria were: in all studies in which patients were treated by ACDF. Studies focused on QOL in such patients, per and postoperative QOL comparisons in patients treated by $\mathrm{ACDF}$.

2.3 Exclusion criteria: case series, patients treated by other methods than ACDF, All the selected papers were then reviewed by two researchers separately to conclude all the information. Initially 220 paper were included; out which 80 found to be relevant, out of them 40 got final selection for review.

\section{Result}

Depression prior to surgery for degenerative cervical disc disease and was found to be present in $11.7 \%$ of patients ${ }^{[9]}$. Bohlman et al. 2 reported $67 \%$ of patients with no neck/arm pain 20 to 33 years after initial surgery at single or multiple levels. In their series, $88.5 \%$ of patients had no functional deficit after surgery compared with $45 \%$ with motor deficit and $63 \%$ with sensory deficit preoperatively. In addition, $80 \%$ of their patients were able to return to work after surgery and maintain socially and economically productive life. These results are "excellent" by all standards and continue to reaffirm the success of ACDF procedure ${ }^{[10]}$.

AA. Theologis et al. also showed there is significant increase in SF-36 after surgery ${ }^{[11]}$. MD. Alvin et al. Aslo showed Compared with preoperative health states, the ACDF cohort showed statistically significant improved PDQ (78.5 versus 57.9), PHQ-9 (9.7 versus 5.3), and EQ-5D (0.55 versus 0.68$)$ scores at 1 year postoperatively ${ }^{[12]}$. Stylianos Kapetanakis showed SF-36, Neck Pain, as well as arm pain feature constant improvement during follow-up, with greatest scores presenting at 12 months and NDI presents its best score at 6 months postoperatively ${ }^{[13]}$. According to E. Shiban, K. Gapon arm weakness was observed in $82(61 \%)$ and $34(25 \%)$ cases in the radiculopathy and myelop- athy groups, respectively. This was improved in $69(84 \%)$ and $28(82 \%)$ cases ${ }^{[14]}$. INW. Tian, $K$. Yan study ACDF group showed significant improvement of their JOA scores and NDI from preoperative measurements to the last follow-up. In terms of Odom's scale, $97.1 \%$ of the ACDF patients got excellent or good results ${ }^{[15]}$.

\section{Discussion}

Although less frequent than lumbar degenerative disc disease, cervical disc disease may be much more neurologically compromising due to ana- tomical particularities. Since its first description together with the typical signs and symptoms the operative therapy of cervical disc disease has undergone a changeful evolution over the years ${ }^{[5]}$. Fountas et al. stated in a study that incidence of worsening due to myelopathy was $0.9 \%{ }^{[16]}$. Psychiatric conditions such as mood disorders represent a significant burden to society, with over $50 \%$ prevalence of depression in surgical candidates for chronic neck diease [9, 17]. Some studies also shows pathological changes were present in the paravertebral muscles of patients with severe cervical spine disease causing decreased muscle tone or muscle atrophy ${ }^{[18]}$. Another psychometric study report showed QOL correlated with clinical outcomes and depression, which says in patients with high-level preoperative depression can cause fare worse following surgery $[19,37]$. Although the literature supporting the relationship between psychological conditions and surgical outcomes, and they indicated they believed that psychologists have the necessary tools to predict surgical outcomes, they proposed that the results might have been the result of improper application of empirically established evaluation methods ${ }^{[19,33]}$. So quality of life is one of the most important measure to check the outcome of surgery. Maratos et al.18 concluded that spine surgery improves both physical and psychological condition and that psychological factors have no independent effect on surgical outcome. Based on their conclusion, surgery that improves physical health might cause psychological conditions to improve as a result of pain relief and other benefits ${ }^{[19,34]}$. Until now, cervical degenerative disc disease that causes radiculopathy/myelopathy has been successfully managed via ACDF for the last five decades with the satisfactory outcomes of ACDF ${ }^{[20,35]}$. In an effort to measure the treatment outcomes objectively from a patient's perspective, current randomized clinical trials and longitudinal studies often require a measurement of pain, function, and general health. Validated outcome instruments, such as the SF-36, NDI, VAS, Odom's criteria, Beck Depression Inventory scale and pain intensity scales represent objective tools to measure these domains. Utilizing pretreatment scores, treatment outcomes can be assessed at 
designated post treatment intervals, evaluating short- and long-term treatment effects ${ }^{[21,22,36]}$. Patient satisfaction with ACDF for cervical spondylotic myelopathy has been reported to range from approximately $75 \%$ to $90 \%$ [23, 38, 39, 40]. When it comes to radiculopathy most of patients are conservatively treated but if surgery is required then most common procedure is ACDF and most common disc involved are C6 and $C 7{ }^{[3,44,45,46]}$. There are also some complications related to $\mathrm{ACDF}$ as a recent study reported an overall revision rate of $15 \%$ in patients who underwent ACDF for radiculopathy or myelopathy ${ }^{[47]}$. Hilibrand et al. studied a consecutive series of 374 patients who had undergone ACDF and reported that symptomatic adjacent segment disease occurred in $2.9 \%$ of them per year, with a cumulative rate of $25 \%$ in a 10 -year period $[15,41]$. Beside all the complication there are lot of studies showed the significant improvement in postoperative quality of life. Some recent studies also accepted the effect of anxiety and depression on the outcome so they have stated to have a preoperative education and found to be beneficial by most authorities. Previous meta-analyses have reported the effectiveness of PE. For example, Devine20 found that patients who received PE spent less time (1.5 days) in the hospital. Hathaway 21 reported that PE reduced fear and anxiety ${ }^{[24,42,43]}$. So it is most important to include quality of life while considering the outcome of a surgery.

Limitation to the study there were very limited studies that have included quality of life measures in their outcome. Secondly studies which were included had different follow up time and last all studies have different quality of life measure whereas SF-36, NDI and VAS were common.

\section{Conclusion}

As the literature states that $\mathrm{ACDF}$ is most common or procedure of choice for cervical spondylosis in past decades. We have concluded that it important to take in count the QOL while checking outcome of ACDF. As there many physical as well as psychological factors that are very important from the patients prospective of life quality. In our study we found ACDF significantly improves QOL in cervical spondylitic patients and most common influencing factors were anxiety, depression and pain.

\section{Reference}

1. Takagi I, Eliyas JK, Stadlan N, Cervical Spondylosis: An Update on Pathophysiology, Clinical Manifestation, and Management Strategies, Disease-a-Month. 2011; 57(10):583-591.

2. Singh S, Kumar D, Kumar S. Risk factors in cervical spondylosis, J Clin. Orthop. Trauma. 2014; 5(4):221-226.

3. Journal AS. Cervical Radiculopathy: Incidence and Treatment of 1, 420 Consecutive Cases, 2016, 0-6.

4. Radhakrishnan K, Litchy WJ, Michael O'Fallon W, Kurland LT. Epidemiology of cervical radiculopathy: A population-based study from Rochester, Minnesota, 1976 through, 1990, 1994, 117.

5. Korinth M. Treatment of Cervical Degenerative Disc Disease-Current Status and Trends, Zentralblatt für Neurochir-Cent. Eur. Neurosurg. 2008; 69(3):113-124.

6. Neck Disability Index, short form-36 physical component summary.

7. Peolsson A, Hedlund R, Vavruch L, Oberg B. Predictive factors for the outcome of anterior cervical decompression and fusion. Eur. Spine J. 2003; 12(3):27480.

8. Peolsson A, Vavruch L, Öberg B. Predictive factors for arm pain, neck pain, neck specific disability and health after anterior cervical decompression and fusion, Acta Neurochir. (Wien). 2006; 148(2):167-173.

9. Jabłońska R, Ślusarz R, Krï ¿1/2likowska A, Haor B, Antczak A, Szewczyk M. Depression, social factors, and pain perception before and after surgery for lumbar and cervical degenerative vertebral disc disease, J Pain Res. 2017; 10:89-99.

10. Jawahar A, Nunley P. Total disc arthroplasty and anterior cervical discectomy and fusion in cervical spine: competitive or complimentary? Review of the literature. Glob. Spine J. 2012; 2(3):183-6.

11. Theologis AA. Psychological Distress. 2013, 2016; 25:4615.

12. Alvin MD. The Impact of Preoperative Depression and Health State on Quality-of-Life Outcomes after Anterior Cervical Diskectomy and Fusion, Glob. Spine J, 2015, 306-313.

13. Kapetanakis S, Thomaidis T, Charitoudis G, Pavlidis P, Theodosiadis P, Gkasdaris G. Single anterior cervical discectomy and fusion (ACDF) using self- locking standalone polyetheretherketone (PEEK) cage: evaluation of pain and health-related quality of life, J Spine Surg. 2017; 3(3):312-322.

14. Shiban E, Gapon K, Wostrack M, Meyer B, Lehmberg J. Clinical and radiological outcome after anterior cervical discectomy and fusion with stand-alone empty polyetheretherketone (PEEK) cages, Acta Neurochir. (Wien). 2016; 158(2):349-355.

15. Tian W, Yan K, Han X, Yu J, Jin P, Han X. Comparison of the Clinical and Radiographic Results Between Cervical Artificial Disk Replacement and Anterior Cervical Fusion: A 6-Year Prospective Nonrandomized Comparative Study, Clin Spine Surg. 2017; 30(5):E578e586.

16. Tasiou A. Anterior cervical spine surgery-associated complications in a retrospective case-control study, J Spine Surg. 2017; 3(3):444-459.

17. Phan K. Relationship between depression and clinical outcome following anterior cervical discectomy and fusion, J Spine Surg. 2017; 3(2):133-140.

18. Wharton SB, Chan KK, Pickard JD, Anderson JR. Paravertebral muscles in disease of the cervical spine, J. Neurol. Neurosurg. Psychiatry. 1996; 61(5):461-465.

19. Young AK, Young BK, Riley LH, Skolasky RL. Assessment of presurgical psychological screening in patients undergoing spine surgery: use and clinical impact. J Spinal Disord. Tech. 2014; 27(2):76-9.

20. Pandey PK, Pawar I, Gupta J, Verma RR. Comparison of Outcomes of Single-Level Anterior Cervical Discectomy with Fusion and Single- Level Artificial Cervical Disc Replacement for Single-Level Cervical Degenerative Disc Disease, Spine (Phila. Pa. 1976). 2017; 42(1):E41E49.

21. Devine J. Evaluating the correlation and responsiveness of patient-reported pain with function and quality-of-life outcomes after spine surgery, Spine (Phila. Pa. 1976). 2011; 36(21):69-74.

22. Teles AR, Khoshhal KI, Falavigna A. Why and how should we measure outcomes in spine surgery? J Taibah Univ. Med. Sci. 2016; 11(2):91-97.

23. Fujimori T. Patient satisfaction with surgery for cervical myelopathy due to ossification of the posterior longitudinal ligament, J Neurosurg. Spine. 2011; 14(6):726-733. 
24. Papanastassiou I, Anderson R, Barber N, Conover C, Castellvi AE. Effects of preoperative education on spinal surgery patients, SAS J, 2011; 5(4):120-124.

25. Miller JA, Derakhshan A, Lubelski D. The impact of preoperative depression on quality of life outcomes after lumbar surgery. Spine J, 2015; 15:58-64.

26. American Society of Anesthesiologists Task Force on Chronic Pain M, American Society of Regional A, Pain M. Practice guidelines for chronic pain management: an updated report by the American Society of Anesthesiologists Task Force on Chronic Pain Management and the American Society of Regional Anesthesia and Pain Medicine. Anesthesiology, 2010; 112:810-33

27. Stoffman MR, Roberts MS, King JT Jr. Cervical spondylotic myelopathy, depression, and anxiety: a cohort analysis of 89 patients. Neurosurgery. 2005; 57:307-13, 307-13.

28. He J, Xiong W, Li F. Depression influences pain and function after cervical disc arthroplasty. J Neurosurg Sci. 2017; 61:39-45.

29. Alvin MD, Miller JA, Lubelski D. The Impact of Preoperative Depression and Health State on Quality-ofLife Outcomes after Anterior Cervical Diskectomy and Fusion. Global Spine J, 2016; 6:306-13.

30. Oglesby M, Fineberg SJ, Patel AA. Epidemiological trends in cervical spine surgery for degenerative diseases between 2002 and 2009. Spine (Phila Pa 1976). 2013; 38:1226-32.

31. Marawar S, Girardi FP, Sama AA. National trends in anterior cervical fusion procedures. Spine (Phila $\mathrm{Pa}$ 1976). 2010; 35:1454-9.

32. Cowan JA Jr, Dimick JB, Wainess R. Changes in the utilization of spinal fusion in the United States. Neurosurgery. 2006; 59:15-20, 15-20.

33. DeBerard MS, Masters KS, Colledge AL. Pre-surgical psychological screenings for lumbar fusion: a look at real world practice. Psychol Health Med. 2002; 7:411-424.

34. Maratos EC, Trivedi R, Richards H. Psychological distress does not compromise outcome in spinal surgery. Br J Neurosurg. Epub ahead of print, 2012. 10.3109/02688697.2011.644821

35. Sasso RC, Best NM, Metcalf NH, Anderson PA. Motion analysis of Bryan cervical disc arthroplasty versus anterior discectomy and fusion: results from a prospective, randomized, multicenter, clinical trial. J Spinal Disord Tech. 2008; 21:393-9.

36. Mannion AF, Elfering A, Staerkle R, Junge A, Grob D, Dvorak J. Predictors of multidimensional outcome after spinal surgery. Eur Spine J. 2007; 16(6):777e786

37. Falavigna A, Righesso O, Teles AR, Baseggio N, Velho MC, Ruschel LG. Depression subscale of the hospital anxiety and depression scale applied preoperatively in spinal surgery. Arq Neuropsiquiatr. 2012; 70(5):352e356.

38. Chagas H, Domingues F, Aversa A, Vidal Fonseca AL, de Souza JM. Cervical spondylotic myelopathy: 10 years of pro-spective outcome analysis of anterior decompression and fu- sion. Surg Neurol. 2005; 64(1):S30-S36.

39. Riew KD, Buchowski JM, Sasso R, Zdeblick T, Metcalf $\mathrm{NH}$, Anderson PA. Cervical disc arthroplasty compared with ar-throdesis for the treatment of myelopathy. J Bone Joint Surg Am. 2008; 90:2354-2364.

40. Sampath P, Bendebba M, Davis JD, Ducker TB. Outcome of patients treated for cervical myelopathy. A prospective, multi- center study with independent clinical review. Spine. 2000; 25:670-676.

41. Hillibrand AS, Carlson GD, Palumbo MA. Radiculopathy and myelopathy at segments adjacent to the site of a previous anterior cervical arthrodesis. J Bone Joint Surg Am. 1999; 81:519-528.

42. Devine EC. Effects of psychoeducational care for adult surgical pa- tients: a meta-analysis of 191 studies. Patient Educ Couns. 1992; 19:129-42.

43. Hathaway D. Effect of preoperative instruction on postoperative out-comes: a meta-analysis. Nurs Res. 1986; 35:269-75

44. Fager CA. Management of cervical disc lesions and spondylosis by posterior approaches. Clin Neurosurg. 1977; 24:488-507.

45. Murphey F, Simmons JC, Brunson B. Chapter 2. Ruptured cervical discs, 1939 to 1972 . Clin Neurosurg. 1973; 20:9-17.

46. Kelsey JL, Githens PB, Walter SD. An epidemio- logical study of acute prolapsed cervical interverte- bral disc. J Bone Joint Surg Am. 1984; 66:907-14.

47. Van Eck CF, Regan C, Donaldson WF, Kang JD, Lee JY. The revision rate and occurrence of adjacent seg-ment disease after anterior cervical discectomy and fusion: a study of 672 consecutive patients. Spine (Phila Pa 1976). $2014 ; 39: 2143-7$ 